\title{
Author Biography:
}

Payal Arora (Ed.D Teachers College, Columbia University, New York; MEd. Harvard University) is an Assistant Professor in the Department of Media and Communication at the Faculty of History, Culture and Communication, Erasmus University Rotterdam, The Netherlands. She is the author of "Dot Com Mantra: Social Computing in the Central Himalayas," a book published by Ashgate on new media usage in India. Her upcoming second book by Routledge, "Virtual and Real Leisure Spaces: A Comparative and Cross-Cultural Analysis" investigates contemporary public leisure space from a historical and transnational lens. Her expertise lies in social computing, cybercultures, new media literacies, and international development. Her work has been published in several international peer-reviewed scholarly journals and as book chapters. Her paper on digitalization of healthcare information in 2010 won the Best Paper in Social Informatics Award by the American Society for Information Science and Technology (ASIS\&T). She is the recipient of the EUR Fellowship Award for 2012-2014. For more details including contact information, visit her website: $\underline{w w w}$.payalarora.com 
To cite: Arora, P. (2012). Typology of Web 2.0 spheres: Understanding the cultural dimensions of social media spaces, Current Sociology, 60: 599-618.

Title

Typology of Web 2.0 spheres: Understanding the cultural dimensions of social media spaces

\author{
Author \\ Payal Arora \\ Department of Media and Communication \\ Faculty of History, Culture and Communication, Erasmus University Rotterdam \\ The Netherlands \\ arora@eshcc.eur.nl \\ www.payalarora.com
}

\begin{abstract}
It has taken the past decade to commonly acknowledge that online space is tethered to real place. From euphoric conceptualizations of social media spaces as novel, unprecedented and revolutionary an entity, the dust has settled, allowing for talk of boundaries and ties to real-world settings. Metaphors have been instrumental in this pursuit, shaping perceptions and affecting actions within this extended structural realm. Specifically, they have been harnessed to architect Web 2.0 spaces, be it chatrooms, electronic frontiers, homepages, to information highways for policy and practice. While metaphors are pervasive in addressing and normalizing new media spaces, there is less effort channeled into organizing these digital domains along cultural lines to systematize and deepen understandings of its histories, agencies and communities. Hence, this paper proposes a framework that reveals dominant cultural dimensions of Web 2.0 spaces through a five-fold typology: 1) utilitarian-driven 2) aesthetic-driven, 3) context-driven, 4) playdriven and 5) value-driven. This effort capitalizes and transfers mappings of actors and networks from real to virtual space to capture and organize diverse cultural (re)productions.
\end{abstract}

Keywords: Web 2.0, digital cultures, social media, virtual spheres, metaphors

\title{
Introduction
}

Common understandings of online space has transformed substantively since its inception, revealed by the shift in terminology from 'cyberspace' to 'Web 2.0.' This new conceptualization comes with an acknowledgement that virtual space is not a monolithic structure but a plurality of networks shaped by its actors (Haythornthwaite, 2005). Further, there has been a growing demand to anchor these spaces in real-world infrastructures rather than accept the initial 
interpretation of such spaces as revolutionary, unprecedented and novel (Baym, 2009).

Metaphors have been faithfully employed in this pursuit, clarifying and making tangible the unknown through the known (Lopez, 2003). There is a clear mission to architect social media spaces through experienced and experiencing physical structures, be it chatrooms, electronic frontiers, homepages, to information highways. Focusing on the spatial dimension emphasizes the importance of the underlying structure -its nature and design in shaping online social action.

Such rhetoric has been harnessed strategically across disciplines: scholars of law draw upon metaphors to transfer legal code from physical to virtual worlds (e.g. Lemley, 2003); scholars of policy use metaphors to simplify and communicate technological novelty and justify new commitments in ecommerce, egovernment, to elearning (e.g. Sawhney, 2007); scholars of architecture and urban planning celebrate the metaphor as it serves as an important reminder of how central their field is in shaping new public space and offer their design strategies to construct online social networks (e.g. Wilson, 2001).

While metaphors are aplenty to explain, argue, and normalize Web 2.0 spaces, they are scattered across disciplines, issues, and fields. Also, they are often engaged in a peripheral manner, rarely pushing these comparative nodes to delve deeper into how networks are created, sustained, and transformed through social action (Sassen, 2002; Yen, 2002). Further, this can be viewed as an opportunity to extend the conversation on relations between culture and social structure to the online sphere (Pachucki and Breiger, 2010). Thereby, there is a need for a framework that organizes and deepens our understandings of the diverse emergent spaces of Web 2.0 by focusing on their dominant cultural arenas and situating them in real-world infrastructures. 
To systematize this endeavor, this paper proposes a five-fold typology that captures the cultural dimensions of new media spaces: 1) utilitarian-driven, 2) aesthetic-driven, 3) contextdriven, 4) play-driven and 5) value-driven. Specific examples of physical infrastructures, their histories and politics are used to illustrate each typology. Actor-network theory is seen as a useful tool to flesh out social relations and concrete mechanisms that hold these cultural networks together (Pinch and Bijker, 1987). To make this case, the paper is organized as follows: the debate of culture and structure and its extension to the online sphere; the role of metaphors in conceptualizing and normalizing new technology space and its situatedness in real place, followed by the proposition and illustration of the typologies to organize the cultural dimensions of new media spaces.

\section{Intersection of cultures and networks online}

Discourse on social networks, especially within new media studies, gives us at times the impression that these are new conversations that are inspired by digital media platforms (Papacharissi, 2002). However, the investigation of social networks has been the core pursuit of sociological inquiry, particularly in its ties to culture (Lopez, 2003). The relationship between culture and networks has been reexamined over the decades: 'culture' has shifted in being viewed as national character, value and identity to that which is local practice, discourse and meaning. 'Networks' has also evolved in its meaning from stable and static systems causing action to structures that are dynamic, negotiating, and culturally embedded. We have come quite a distance from the pronouncement of Blau's "social structure is not culture" $(1977$, p. 245$)$ to current theorizations that "networks and culture are mutually constitutive and so deserve deeper analytic consideration in light of one another" (Pachucki and Breiger, 2010, p. 209). 
Thereby, this paper builds on this premise that the virtual sphere is constituted with diverse social network spaces, each with their own cultural elements, This also answers the current call by Pachucki and Breiger (2010) and extends this discussion to the online realm wherein:

...the time is overdue for a conscientious shift beyond cultural explanations for social structure, and structural explanations for cultural outcomes, toward a more integrated vision of social scientific explanation. Social relations are culturally constituted, and shared cultural meanings also shape social structure (p.219).

That said, creating a framework for understanding different online social structures through the lens of their culture is not sufficient. What is needed is to deepen such investigations through a more systemic way; analyzing actor nodes, social positions, relations, histories, mobilities, and communicative practices allows for a comprehensive outlook on cultural (re)productions that defines and gives specific virtual spaces its endemic character. Hence, actor-network theory (ANT) is a useful methodological tool to employ for such purposes (Pinch and Bijker, 1987). In essence, developed within the science and technology field, it is a social scientific method of mapping relations between the material (e.g. new technologies and its spaces) to the semiotics (concepts). Thereby, a social network entails a host of actors (both material and semiotic) coming together in the enactment and reproduction of its specific cultural space. By paying attention to how offline performances overlap with that online, much insight can be gained on how social practice extends and/or transforms the virtual realm.

\section{The Metaphor as King}

The metaphor today enjoys central status. Over the past half-century, metaphors have shifted position from being peripheral in discussions to now an essential part of conceptual reasoning (Johnson, 2010). Seen in prior days as a mere figure of speech, it is now viewed as a critical 
cognitive device that allows us to unpack complexity and normalize novelty by extending the meaning of content/context to which it is applied (Ricoeur, 1977). Lopez (2003) argues that the usage of metaphors is unavoidable in social theory and yet, continues to be often neglected. Metaphors, he states, can be powerful instruments for social theorists to understand 'structure,' not constructed as opposed to or in association with agency but rather, constitutive of each other. What is useful for this paper is his highlighting of the 'architectural metaphor' approach which is capitalized to reveal networks of concepts that serve to map social reality. This can have a cognitive impact especially when it is not just descriptive of a particular social domain but generative in function. Using the example of the 'eye is a camera' metaphor, he illustrates how common knowledge of how the camera works can serve to explain the complexities of the eye and produce new vocabularies to capture these new understandings.

However, he warns us of the danger of metaphors serving as mere transfer mechanisms of meaning rather than a transformative one:

A transfer also sets up a relationship between the host domain and another phenomenological domain; however what distinguishes it from a transformation is that it fails to produce new domain specific concepts, meanings, and theoretical strategies in the host domain. (p. 16)

Some popular examples he draws upon to illustrate the flawed and misleading metaphorical application is Durkheim's ‘society as organism' metaphor indicating evolutionary and deterministic notions of social structure, Marx’s 'base-superstructure' metaphor fostering dichotomy and causality of social relations to Parson's utilization of thermodynamics terminology that dangerously took us on the path of viewing social domains as systems of equilibrium, homeostasis, adaptation. Hence, this paper embeds the usage of actor-network theory within its metaphorical framework to circumvent deterministic leanings. 
When applying metaphors to abstract domains, it is important to remember that we do not transfer in entirety all the meanings from one context to another (Schmidt, 2002). Instead, the aspect that is in most need of comprehension is tied to the original and familiar context:

... by using concrete experiences to express abstract matters we always use one aspect of the domain of origin - not every aspect which in its own way is relative to culture-bound ways of mapping concepts. (p.2)

Furthermore, metaphors are not just cognitive tools to map and comprehend social reality and aid in social science research but can also be potent policy tools to communicate and convince vast audiences of new initiatives. Based on how it frames an issue, it can push policy agendas in fields wide ranging as immigration, telecommunications, education and war (Lakoff and Johnson, 1980; Lemley, 2003; Sawhney, 2007). An example that has gained attention (and is described in more detail in the utilitarian-driven section of this paper) is the usage of the ‘information highway’ metaphor to describe the Internet. Stefik (1996) argues that this early metaphorical adoption severely limited public perception and expectation of this digital domain, narrowing conversations to the access of information but lacking guidance in the usage of this information. That said, metaphors can be as much a cause of policy as a product of such enactments. For the purpose of this paper, we focus on the spatializing role of the metaphor as it maps physical space onto virtual space and through these means reveal its prime cultural dimensions.

\section{The Metaphor as a cyber-architect}

Metaphors can be powerful tools to construct and comprehend virtual space by overlapping the physical onto the digital domains. As expounded in the earlier section, for metaphors to be effective, it needs to focus on a specific online aspect to highlight, facilitate and critique. For 
instance, Mitchell (1996) compares the Net to the city to draw attention to the fact that while digital space appears infinite and freely accessible, it is subject to accessibility constraints and regulatory factors:

If the value of real estate in the traditional urban fabric is determined by location, location, location (as property pundits never tire of repeating), then the value of a network connection is determined by bandwidth, bandwidth, bandwidth. Accessibility is redefined. (p. 17)

Also, by situating these investigations within real space, it avoids "a purely technological interpretation and recognizes the embeddedness and the variable outcomes of these technologies for different social orders" (Sassen, 2002, p. 837). In fact, adopting spatial metaphors to understand virtual space indicates that there is an implicit agreement that the Internet has spatial characteristics in common with real-world places (Hunter, 2003). In other words, "it seems logical that an examination of how we comprehend geographic space might reveal insights and lines of enquiry into how we spatially comprehend cyberspace" (Shum, 1990). Hence, it is no coincidence that one of the most popular initial spatial metaphors employed to grasp the Internet domain was that of 'cyberspace,' albeit not without controversy:

Adherents of the 'cyberspace' metaphor have been insufficiently sensitive to the ways in which theories of cyberspace as space themselves function as acts of social construction. Specifically, the leading theories all have deployed the metaphoric construct of cyberspace to situate cyberspace, explicitly or implicitly, as separate space. This denies all of the ways in which cyberspace operates as both extension and evolution of everyday spatial practice. (Cohen, 2007, p.210)

Another case in point is the popular usage of the 'new frontier' metaphor to celebrate the democratic potential of the digital public sphere. At the onset, the Internet was paralleled to the 'Western Frontier' where "land was free for the taking, where explorers could roam, and communities could form with their own rules. It was an endless expanse of space: open, free, and replete with possibility" (Hunter, 2003, p.3). This metaphor carried with it the notion of the 
American 'land of opportunity' and 'pioneering spirit' that took this comparison beyond the mere geophysical domain to that which is ideological - a space of limitless possibility and individual agency. This resulted in popular conviction that the Net needed to be kept free from state regulation to maximize individual potential. Yet, Yen (2002) reminds us that when adopting such metaphors to push for deregulation, we need to keep in mind the trade-offs that ensued during this supposed golden-era as tremendous historic injustice and exploitation took place during its time. Capitalizing on the complexities of the past can enhance the understandings of the present and create insightful planning for future policy, especially given the fact that rhetoric often gets reified.

In fact, since this initial frontier comparison, numerous studies have come out to critique this utopic notion of the Internet, emphasizing instead the range of virtual exclusions, colonizations, and migrations into the infosphere (Castronova, 2001; Gunkel and Gunkel, 1997; Sardar and Ravetz, 1996). However, utopic notions continue to persist as remarked by Gunkel and Gunkel (2009) where to their astonishment, they find that two decades later these metaphors have found their way into architecting and designing massively multiplayer online role playing games (MMORPGs) with little acknowledgement of past critiques and tensions of this metaphorical application. Such peripheral engagements with rhetoric happen time and again, perpetuating misleading conceptions of the past and flawed rationale for the future. Hence, it is essential when transforming virtual space through the metaphor of real space, to situate our understandings in existing social and cultural practices as well as its histories. Baym (2009) argues that paying heed to socio-cultural behaviors and relations will effectively reveal diverse and contesting practices, and a more nuanced and sophisticated understanding of the Web 2.0 as a plurality of cultural spaces. So, contemporary scholarship on virtual geographies for the most 
part agree that there is no uniform, universal and monolithic digital sphere but a host of niche spaces within this domain. Also, there is some agreement on the fact that the Web 2.0 is not a novel and utopic space but a realm which is shaped by socio-cultural action and human relations.

Of course, it is understandable how at the birthing of the Internet, there was a dominant trend to disengage and disassociate from physical place. It's about the promise that it brought for a new public sphere where "ideas of citizenship, commonality, and things not private, but accessible and observable by all" could come to fruition (Papacharissi, 2002, p.9). Viewing contemporary public space as limited and limiting, to even a failed arena, this novel virtual space became associated with individual self-fulfillment and personal development. A new democratic dream was born. Part of this disassociation came with the denying of form to this nebulous structure. By disregarding conventional mappings onto Web 2.0 spaces, it was seen as being liberated from the shackles of real world boundaries and territories. Taken further, it was compellingly argued that chronic power inequities are embedded in our physical world, and unlike this reality, the virtual sphere is inherently free.

However, with every utopian declaration comes a dystopian reaction. Universal access and usage of the Internet continues to be unrealized with tremendous disparities in access; while the United States enjoys almost $80 \%$ access, only $11 \%$ of the African population has the same opportunity (Internet World Statistics, 2011). Thereby, this 'novel' space becomes yet another realm for manifesting and perpetuating inequality. Turning the tables around, euphoria is replaced with apprehension - fear of this "elite space" becoming the new "playground for the privileged" (Hess, 1995, p. 116). This time, however, it is seen to be at an unprecedented and globally ambitious scale that threatens to exponentially increase the divides between people and cultures. Such utopia/dystopia visions and proclamations confront histories and current practice 
wherein it is seen that people often times evoke, imitate and simulate behaviors and spaces of the physical world within virtual spaces. In other words, the novelty of the technological realm is seen to not automatically determine novelty in social action. For instance, virtual communities, some argue, are not being formed as enthusiastically expected with inherently new and noble social rules but rather, are often building on and extending offline relationships (Baym, 1998). Similarly, legal, educational, governmental, commercial and other spatial practices are seen as being fundamentally integrated with the online realm (Leander and McKim, 2003; Hampton and Wellman, 2003). Blurring of these online and offline spheres has inspired new avenues of scholarship, embarking on fleshing out the embedding and embodied aspects of this new perspective. From isolated and exclusive worlds, the virtual and the real are now enmeshed and entangled; a cornucopia of realities now inhabits this united space. What is needed is an organization of this relationship by identifying the dominant practices online and grouping them according to the nature, design, and culture of its virtual arenas.

Hence, the focus of metaphor usage is not just to highlight and comprehend the novel aspects of these new media spaces but to connect these disparate user-generated online spaces into a more coherent and multiplexed model. Stefik (1996) was one of the earlier scholars who proposed the digital realm as multiple spatial archetypes, emphasizing on the utilization of information than on its access. As an alternative to the popular 'information highway' metaphor to describe the Internet, Stefik suggested the adoption of four metaphors, each focusing on a different facet: 1) Internet as the digital library, 2) as electronic mail, 3) as the electronic marketplace, and 4) as digital worlds. Basically, he drew parallels of each of his metaphors to the Jungian archetypes of the keeper of knowledge, the communicator, the trader/warrior, and the 
adventurer. Dominant however in this model is its utilitarian nature which focuses on the usage of information, with less emphasis on the cultural dimensions of social media space.

Of course, Appadurai’s classic ‘technoscapes' metaphor (1996) was embraced enthusiastically at its onset and arguably continues to hold influence as it contested the Americanized perception of the digital sphere (made obvious with the adoption of the 'Western frontier' metaphor) and the lack of emphasis on the connectivity and mobility within and between diverse cultural spaces. His metaphor shifted focus away from the homogenization of online space and instead, offered a new conceptual framework to grasp the globalizing nature of this virtual sphere. This metaphorical proposition dismisses boundaries and focuses on flows between these spaces to highlight contemporary global configurations between nations, technologies, people, and ideas. However, the significant trade-off here is that it sacrifices the architecting and grounding of digital spaces and takes it back to a nebulous space which is unbounded and seamless.

In fact, there are several instances where spatial metaphors have been used to construct digital space, harnessing on familiar physical terrains. Some examples are Kendall's usage of 'virtual pubs' (2002) to focus on gender identities and interaction online; the metaphor of 'electronic ghettos' to emphasize the confinement and entrapment of the poor and marginalized into 'information black holes' where gender, ethnicity, class and other factors play a part in limiting their access and opportunities within this supposed open digital realm (Graham and Marvin, 2005). Hence, contrary to democratic and utopic notions of the Web 2.0, is a reality that there are deep segmentations, segregations and social struggles in accessing these privileged digital domains. Another interesting spatial parallel is the concept of 'cybermalls' that captures the exponential growth of commercial sites online as well as the physical birthing of malls across 
the globe from the Middle East, Brazil, India and China, signifying the traveling of branding, consumer behavior and cultural norms that dictate these spaces, online and offline (Cohen, 2007). While there are several metaphorical applications connecting online with physical space to define, problematize and shape the digital realm, there are few studies that attempt to provide a comprehensive framework that leverages on the histories, cultures and politics of diverse physical places to highlight the equally diverse virtual sphere.

\section{Typologies of online space}

This paper proposes a five-fold, metaphor-based typology to comprehend and organize the dominant cultures of Web 2.0 spaces. These cultural realms are architected, designed and driven by certain intent of its engaged actors: 1) utilitarian-driven, 2) aesthetic-driven, 3) contextdriven, 4) play-driven and 5) value-driven (Chart 1). This framework allows for an exploration of online space through physical place, serving as spatial metaphors. Specific aspects of the material world are transposed onto the virtual based on particular conceptual aspects online that is in need of attention. Actor network theory is embedded in this metaphorical process of transfer and transformation to allow us to unravel social relations, histories and positions of actors that perform the making and sustenance of each of these online cultural realms.

The choice of such typologies is by no means arbitrary. Popular metaphors that have captured academic and mass media discourse such as the information superhighway aid in these decisions. Popular trends such as the virtualization of museums and the exponential rise of cyber-leisure realms such as social network sites impact these categories. Popular Web 2.0 debates such as the relationship between private and public arenas, utilitarian versus leisure/play space, free versus commercial/commoditized space and open versus closed systems dictate these 
groupings (Lemley, 2003; Rheingold, 1993; Sassen, 2002; Sawhney, 2007; Wellman and Hampton, 2003). While undoubtedly this model cannot incorporate all debates, it does strive to capture the dominant ones and offers a spatial lens through which these discussions can be addressed. As with all boundaries, these categorizations are porous and overlapping as the culture of an online space can be, at once, both utilitarian and aesthetic driven for instance. However, when metaphors emerge and are embraced by the media, they often center on particular phenomena such as socializing, customization, and personalization, or, more specific activities like shopping, banking, and schooling. Thereby, we use this typology to, a) highlight the prevalent cultures within Web 2.0; b) recognize the dominant conversations taking place on a particular type of online space; c) detect the most appropriate metaphors that illustrate this typology; d) unravel its social relations that sustain these cultural networks; and e) determine the extent of the transference between the physical and virtual realms that could lead to further comprehension, prediction, and innovation.

To operationalize this typology, this paper illustrates each category through select physical architectures such as highways, homes, museums, parks, and playgrounds, their histories and topologies, to illuminate the online and offline linkage. Given this is a model that is constructed versus adopted, a good portion of this paper focuses on justifying the metaphorbased framework as well as describing these different typologies to create a clear picture of these categories. Of course, this comes at a price where illustration of each typology is more peripheral than in-depth. That said, there is expectation that, as with all frameworks, it will be adopted, operationalized and experimented with, serving as grounds for future scholarship.

\section{Utilitarian-driven space}


The Internet is dominantly viewed as a space of utility. It is intended for certain purposes and such intentions manifest through metaphors of expectation and aspiration. This type of space is marked by its service to society, its practical implications and predications. The nature of this online space lies in its innate need to be functional and optimal in its design and usage.

To illustrate this category, let's focus on the much used metaphor, information superhighway. In the 1990s, the then United States senator Al Gore popularized this metaphor as a way of underlying the importance of the ambitious undertaking of high-speed communication systems (Benjamin and Wigand, 1994). A global information infrastructure was being formulated, with numerous alliances fostered across states and the private sector. To converge different technologies such as the telephone, television and the computer, there required the need to partner with several and often competing organizations. Connectivity was and still is the byword. At the US Senate commerce committee in 1990, Senator Hollings ${ }^{\mathrm{i}}$ advocated this vision:

Simply put, fiber to the home, school and business is an essential infrastructure for economic development in the Information Age of the 21st century, just as railroads were in the last century, and highways [italics added] were in this century.

While this metaphor is no doubt useful to highlight the scaling of technological infrastructures, if propelled further, it can garner deeper insights into the actual implementation of such endeavors. For instance, Sawhney (1992) capitalized on the different stages in the development of highways to structure and predict the growth pattern of the telecommunications infrastructure, "the generalizability of this model is tested by comparing its conceptual framework with the historical data on the development of the highways and automobiles" (p.541). Through this metaphorical strategy, he was able to trace commonality in the recurring pattern on how a new technology 
space starts as a feeder to the established system and then goes onto displacing that system with the development of long-distance capabilities.

Further, by paying attention to the socio-economic and political issues encountered in the scaling of highway infrastructures, we can perhaps foresee some of the contemporary social concerns when scaling digital infrastructures. For instance, can we readily assume that the information superhighway is to be uncritically celebrated? Can we take on the assumption that highways are inherently and universally good and have been instrumental in connecting disparate communities together, opening spaces for a more egalitarian flow of goods, jobs, and services? Will this infrastructure benefit one and all as promised regardless of economic or/and social status? What exactly is being connected across sectors? What is really moving -ideas, goods, services? Who are the direct and indirect beneficiaries?

So if we further examine the highway as a social and technical network (Kaszynski, 2000), we discover that initially it was used to allow different kinds of traffic from foot to carriage but later on, it streamlined to mainly automobiles. In the 1930s, there was heavy investment by nations into such infrastructures to spur economic and defense systems. Initially, there was emphasis in moving armies and military goods across borders. As it scaled nationally, standardization in design and regulation of such spaces came about: the width, speed, directionality, and signage, to name a few. It became "the 500 mile road without a single traffic light" (Shragge and Bagnato, 1984, p.12). And as people became more accustomed with these highways, these rules became naturalized into their social system. Also, the popularization of the automobile made it more financially accessible, creating incentives to scale highways across the nation. And while these networks did give birth to plenty of economic opportunities and social 
connectivity, it also created new kinds of spaces (suburbia) and often disrupted communities by fragmenting neighborhoods, and breaking local spaces in disparate ways.

On a more contemporary level, with China and India for instance rushing to catch-up with the highway infrastructure, it is worth looking at how these highways are being mapped onto already existing systems of transport. Also, there are pockets of urban planning innovation such as the Monderman Model of 'shared space' in the Netherlands, questioning the typical design of such transportation spaces based on alternative assumptions of human spatial usage. For instance, 'shared space' is based on the premise that highways are not inherently better ways of organizing people's movements and that different modes of transport, from cycles to cars can co-exist successfully.

While it is out of the scope of this paper to analyze the information highway in depth through the history and design of highways, we have here several metaphorical openings to creatively and critically approach issues of interest on Web 2.0 spaces such as the nature and flow of online traffic, fragmentations of online communities, how users behave in common and shared virtual spaces, the digital divide and convergence of old and new media. With some imagination, we can see parallels with the Internet and the highway: how this mode of transport was not as radical and unprecedented as proclaimed but was an extension of existing urban planning that served a similar purpose but lacked its extensity and standardization; we see the trade-offs involved in providing economic opportunity but impacting local community cohesion. We see how technological artifacts and spaces are webbed together: with the automobile becoming feasible, it allowed for the justification of the scaling of highways, a highly costintensive endeavor. This is much like mobile phones, opening up access and usage of the Net at an exponential rate. 
We also see how the shift in focus from the military to the social took place; how standardization gets ingrained and exported to different cultural contexts and yet, if we are to take this further, we will see how cultural nuances play a part in the shaping of how traffic flows, what kinds of rules become universal and how some get replaced by more localized preferences. We can also start to think at a more macro level in terms of associations of online spaces with other technical tools and spaces, and how catching-up has possibly different implications. Also, much can be learnt about the design of space across settings through innovative models based on human adaptability and spatial usage.

\section{Aesthetic-driven space}

If we were merely driven by functionality, we would never have much choice. Human inclination for personalization and need for ownership is an important driving factor in the shaping of space (Lemley, 2003). Aesthetics is a tool that converts the generic into the particular. The debate however is not an either-or between utility and aesthetics but rather, to what extent does aesthetics play a part in shaping online space and how important is it for users to feel at home online? After all, loyalty is not just towards products, but also towards space (Banjamin and Wigand, 1994). It is found that to cater to individual needs, one is not required to come up with individual solutions to each need (Piller, Schubert, Koch, and Moslein, 2005). In fact, users work optimally within some pre-defined structures of space to garner solutions for their individual desires. This can be explained by the fact that desires of personalization are in fact, socially shaped and shared. Thereby, contemporary interest on customization surrounds the codesign process between institutions that provide the larger structure of space and users that inhabit these spaces, through strategic and creative means. 
It is found that there are certain aesthetic ways in which individuals find their 'style' and 'voice' within online spaces (Herring, Scheidt, Bonus, and Wright, 2005). Through a range of visual design elements, users manipulate space, sometimes with gender differences becoming manifest:

....analysis suggests that adult males are most likely, for example, to use unique templates, with teenage females ranking second in their use of customized templates (Scheidt and Wright, 2010, p1)

While the exercise of aesthetics may at times appear to be small alterations to an online space, the nature of toolkits/ applications of the website can make an entire difference on whether or not the user decides to set up home in such a space. So, in populating these tool-kits, assumptions on preferences of tools and how different users use such devices become of fundamental importance: are there differences in taste for instance, between women and men? Ethnicity, gender, class, age, and education can serve as some markers by which these investigations are followed through.

If we were to capitalize on physical spaces, and take on the home metaphor where users become interior designers, we can perhaps gain insight into how aesthetics play a part in the personalizing of online space. For example, Miller's (1988) classic study on social housing of the London Council estate can be an interesting and revealing case in point. In transforming "alienable goods to inalienable culture" (p.353), the inhabitants of social housing, a low-income group managed to appropriate and at times gender these spaces. While this is temporary housing, people inhabit spaces often with a more permanent mindset. They privatize what is considered to be public space through a range of aesthetic choices. In fact, if we were to draw parallels between how different spaces, be it the office, the home, the shop, and the like are treated, we could get a sense of which kinds of spaces do people feel the need to shape and which do they 
feel less involved with? To what extent do they go into personalizing such spaces and how does that impact their commitment to that space in terms of length of inhabitation? What constitutes as the gendering of aesthetics in space? In other words, there is a need to discriminate different online spaces in terms of the level of personal involvement of the user with that space, allowing web designers to decide to what extent they need to provide features that allow for customization. So if we are to take this leap into the online realm, these questions are of tremendous pertinence as diverse sites all strive to attract and sustain their users within their virtual spaces and aesthetics is one such way in which they can feel spatial ownership.

\section{Context-driven space}

Spaces can be grouped according to its situated and embedded practice (Lave and Wenger, 1991). So, for instance, urban park spaces are dominantly oriented towards public leisure while school spaces are dictated by educational activity. Yet, similar space can yield disparate perceptions, and behaviors. Spaces that are designed with common intentions and architectural structures can result in diverse outcomes. For example, while public parks and squares across cultures were designed for similar intended purposes of mass socialization, enculturation, and a safety valve to contain social unrest through leisure, they can differ markedly by the context at hand (Arora, 2011). While the presence of parks is universal, they evoke specific kinds of practices; parks in Manhattan differ from say, Egypt or Cape Town in South Africa in their usage, perceptions, and underlying design. Further, spaces get marked as gendered or elite for instance, depending on whether certain demographics consistently infuse that space.

In fact, the reason why no two spaces are exactly alike is because of sustained reproduced performance with and within such spaces, shaping their character. In other words, the repetition 
of everyday activities within an environment creates a particular experienced setting that comes to be associated with that set of activities. Perhaps that may partly explain for instance, why $M y$ Space is favored by musicians over other social network sites; why Orkut continues to be the most popular in Brazil or why LinkedIn struggles to shrug of its work-related label as it strives to expand into a more social realm. On the other hand, what makes Facebook take off on such a global scale? (Herring et. al., 2005) Utility can explain the functional aspects of social networking sites that enable connectivity. Aesthetics can explain partly why certain sites are preferred over others due to visual appeal and personalization. Context-driven space however, situates social practice at the center when understanding online space. Of course, human usage is always pertinent to spatial understandings but in this category, it achieves central importance.

So if we are to push the parks analogy further and equate it to social network sites, some interesting revelations come through. They both are places that share the same rhetoric - of being universal, public, free for all, democratic, communal and non-utilitarian (Arora, 2011). In fact, parks are commonly perceived as generic public leisure places for communal gatherings, much like social network sites with little formal regulation. If we do a historical take on parks, we see that in the early 20th century, parks in Beijing to Boston were spaces that shifted from the hands of private and State entities to that of the public, with the intent to create a safety valve for social unrest and to civilize the masses (Rosenzweig, 1979; Shi, 1998). This can be paralleled with the history of the Net where it shifted from the hands of the military to the public. Parks also served as a symbol of modernization during that time, much like the signaling effect of computers as progressive across nations. For example, the need to appear 'modern' took root amongst Chinese and American reformers during this time and thereby, led to the opening up of private gardens as public venues for leisure. 
Yet, diversity amongst parks exist and can be attributed to how these spaces are used as well as which groups seem to dominantly use them. Looking at park reformation in Massachusetts in the late 19th century (Rosenzweig, 1979), we see that Worchester parks were specifically intended to control the flow of immigrants into the city that had reached about $60 \%$

of the city population. Given there was high unemployment amongst this populace, the industrial sector saw parks as a way to contain and civilize these immigrants and to socialize them for the State. Thereby, Worchester parks became marked as spaces for immigrants. If we are to take on this approach, we will find that the Ramble in Central Park from the early 1900s became known as a gay hangout (referred as the "fruited plain"), the Speakers corner in Hyde park became a space for political protest and activism, while the promenades of $19^{\text {th }}$ century Paris became strolling grounds for courtship and matrimonial hunting (Arora, 2011). With a short leap, we can draw parallels of such park pluralities with that of online sites where depending on how the site is used and who frequents it, its character gets formed. Hence, LinkedIn sustains its 'culture' through professionals using it while MySpace serves as a musician site as long as new bands continue to choose this space over others to share their creative output. So if we are to figure out the nature of a space, we need to pay attention to dominant and repeated activity within these spaces - who generally uses and interacts within these spaces and for what purposes.

\section{Play-driven space}

In this category, functionality takes a back seat. Efficiency is replaced with engagement, arguably one of the most important ways in which users online are attracted and meaningfully engaged with certain sites. Sometimes, work is ingrained in play spaces to enhance productivity. We see the trend of corporations extending their branding of products and services through 
online play spaces from social networking to gaming sites (McCorkindale, 2010; Banks and Potts, 2010). Also, corporations use such sites to build 'relationships' and loyalty amongst their employees as well as with customers. Sometimes, play is used to engage in serious endeavors of social transformation and education where conventional strategies have perhaps failed. The sanctimony of the serious gets webbed with play, and instead of trivializing the goal, it can give it a new lease to life. We see this with the usage of sites such as Second Life and serious games in general, that aim to entertain and inform at the same time (Brown and Adler, 2008). Also, play spaces can be a strategic platform to appeal to and gain the attention of different demographics. For instance, we see politicians embracing the blogosphere platform to appeal to a younger demographic for political engagement (Malin, 2010).

So, with such cyber-playgrounds, we get to look deeper into the relationship of work and play. In fact, by investigating how organizations and agencies establish play spaces in the physical world for diverse outcomes, we can learn, adopt and transfer such ideas into the online sphere. Take for example the famed Patch Adams ${ }^{\mathrm{ii}}$ idea of converting hospital spaces into places of fun. He is best known for his work as a medical doctor and a clown, using this unusual combination to transform how we perceive and approach healthcare. The shaping of hospital space into a play space is looked upon as an integral part of healing. This makes us question how healthcare organizations and other sectors should represent themselves online through their choices of text, image and other multimodal forms of expression.

Another interesting venture is to look at how pragmatic spaces are converted into fun spaces for social good. For instance, in Stockholm's Odenplan subway station, the staircase has been retrofitted to resemble giant piano keys, which produce real sound, to encourage commuters to climb the stairs rather than ride the escalator. This is specifically initiated to address the 
growing obesity rates amongst the population. In using such 'choice architecture,' (Thaler, Sunstein, and Balz, 2010) to encourage behavior that is good for both individuals and societies, fun spaces is directly associated with behavior change. Thereby, whether it is using second life to engage school children in literacy and mathematics or using serious games to get people to reflect on issues of global warming to animal welfare, there is a growing need to think of alternative and stimulating ways in which we can communicate online and offline.

\section{Value -driven space}

Sentiment towards space is another important driving force that determines user behavior. We choose to inhabit certain spaces based on emotive elements through personal association. Media often shapes how we value certain spaces, be it online or offline. With the tremendous choice online of sites to occupy and experience, the new browser becomes an online tourist, peripherally engaging and being entertained (Burbules, 2009). The digital flaneur (Andrejevic, 2005) strolls through a range of sites, consuming space in a distant manner. Thereby, the need to elicit sentiment becomes one way in which online spaces can sustain the transient electronic masses. Contemporary tourism studies have opened avenues to examine spaces that are multidimensional in its valuation. Smith (2003) expands on the range of tourism sites that have emerged - heritage, urban renewal to educative, revealing people's diverse needs to explore new worlds.

So if we situate this discussion in a particular tourism space, one can look at the virtual museums trend and discussion that has recently emerged. Museums often give value to its surrounding urban space and can revive possibly decaying public spaces; museums are also a way through which a nation builds its brand and identity; and people value museums as spaces of education, enlightenment, and socialization. So, questions emerge: what is the relationship 
between virtual museums and their traditional physical counterparts? Going beyond the natural temporal and spatial limitations of physical collections, such as location, opening hours, display space, are there unique opportunities that virtual museum spaces offer? How do the affective aspects of art consumption transfer online? How are online collections curated, indexed and coded for online users? Is this a viable alternative to the physical, or does the virtual museum serve a different or complementary purpose? (McConnell, Middleton, Smart, and Jeffels, 2004) Juxtaposed against the traditional museum, it is seen that the virtual museum can present exciting opportunities for placing art materials in new contexts that allow them to be reframed. For instance, by indexing art under different categories - contemporary, tribal, or regional, and capturing art searches online by users, it can reveal the politics of information management. In addition, it can result in the widening of access to museums amongst demographics that would not normally use such heritage spaces.

Also, technical possibilities of artificial bots tracking interaction histories and inferring relationships among knowledge pieces and preferences of viewers creates "fluid ontologies" (Srinivasan and Huang, 2005) that allow for a tighter coupling between communities' interests and the browsing structure of a digital museum. This makes web developers a type of new curator. Overall, it reminds us that when interacting online, we often simulate the physical world instead of creating absolutely novel kinds of space. Yet, in such simulations, questions arise of transposing all aspects of the conventional space, including those that are deemed as problematic. Taking the museum illustration, these spaces have been accused of being elitist and entrenched in colonial history, where the ritual of art experience gets to be determined by privileged actors, often from the North. What kinds of art gets represented as canonical, how 
such knowledge structures are shaped and the historical and cultural placement of such artifacts can be re-examined as these practices travel online.

\section{Conclusion}

This paper makes explicit the cognitive impact of metaphors on the conceptualization of Web 2.0 spaces and its cultures as well as the policy implications that come with the communication and embracing of such metaphors. Given its omnipresent usage in normalizing new media spaces as well as the current embracing of its diverse cultural realms through user-generated action, this framework serves as a systemic way to organize spatial metaphors through a cultural lens. Here, the metaphor is pushed to its limits and in doing so, investigates the wide-ranging consequences and trade-offs as well as the cross-cultural impact that these metaphorical parallels bring out and reveal about online usage. This allows us to sensitize ourselves to the diverse consequences on populations, policies, and cultures. Instead of reinventing the wheel on how networks and spatial structures are shaped and sustained by its actors within the virtual sphere, this paper draws readily on critical literature across disciplines that investigate such architecting of spaces in the physical world. It leverages on our accepted understandings that the digital realm is an extension of the real world. Acknowledging that there is no generic and monolithic virtual space, this paper organizes our understandings of the plurality of online spaces through its architectures networks and cultures. Rather than blur the online and offline borders, this framework argues for an organization of these online borders through the aid of how physical structures are constrained and contained. Inherently there is a challenge to talk in broad terms and yet ground our conceptualization. This framework attempts to do so, by addressing larger networks and online structures and yet grounds it through its specific architectures, cultures, histories, human action 
and relation within these virtual spheres. Here, Pachucki and Breiger's call is answered (2010) to create a mutually constitutive relationship between culture and structure by extending this discussion into the online sphere. Overall, as with all frameworks, we should try to view it for what its worth- a conceptual map for clarification and thoughtful discussion.

\section{References:}

Arora P (2011) Online social sites as virtual parks: An investigation into leisure online and offline. The Information Society 27(2): 113-120.

Andrejevic M (2005) Nothing comes between me and my CPU: Smart clothes in the digital enclosure. Theory, Culture, and Society 22(3):101119.

Appadurai A (1996) Modernity at Large: Cultural Dimensions of Globalization. Minneapolis: University of Minnesota Press.

Banks J and Potts J (2010) Co-creating games: A co-evolutionary analysis. New Media \& Society 12(2): 253-270.

Baym NK (1998) The emergence of on-line community. In: Jones S (ed) Cybersociety Communication and Community, pp. 35-68: Newbury Park, CA: Sage.

Baym NK (2009) A call for grounding in the face of blurred boundaries. Journal of Computer-Mediated Communication 14 (3): 720-723.

Benjamin. RI and Wigand RT (1994) Electronic commerce: Effects on electronic markets. Journal of Computer-Mediated Communication 1(3): 1-12.

Blau PM (1977) Inequality and Heterogeneity: A Primitive Theory of Social Structure. New York: Free Press

Brown JS and Adler RP (2008) Minds on fire: Open education the long tail and learning 2.0. EDUCAUSE Review 43(1): 1-19.

Burbules N (2000) Aporias, webs and passages: Doubt as an opportunity to learn. Curriculum Inquiry 30(2): 171-187.

Castronova E (2007) Virtual worlds: A first-hand account of market and society 
on the cyberian frontier. The Gruter Institute Working Papers on Law, Economics, and Evolutionary Biology: 2(1). Available at: http://www.bepress.com/giwp/default/vol2/iss1/art1/ (Accessed on 10 January 2012)

Cohen EJ (2007) Cyberspace as/and space. Columbia Law Review 107: $210-256$.

Graham S and Marvin S (2005) Telecommunications and the City: Electronic Spaces, Urban Places. New York: Routledge.

Gunkel AH and Gunkel D (1997) Virtual geographies: The new worlds of cyberspace. Critical Studies in Mass Communication 14: 123-37.

(2009) Terra nova 2.0 -The new world of MMORPGs. Critical Studies in Media Communication 26(2): 104-127.

Hampton K and Wellman B (2003) Neighboring in netville: How the Internet supports community and social capital in a wired suburb. City and Community 2(3): 277311.

Haythornthwaite C (2005) Social networks and Internet connectivity effects. Information, Communication and Society 8(2): 125-147.

Herring SC Scheidt LA Wright E and Bonus S (2005) Weblogs as a bridging genre. Information Technology \& People 18(2): 142 - 171.

Hess D (1995) Science and Technology in a Multicultural World: The Cultural Politics of Facts and Artifacts. Columbia University Press: New York.

Hunter D (2003) Cyberspace as place and the tragedy of the digital anticommons. California Law Review 91: 441-520.

Johnson M (2010) Metaphor and cognition. Handbook of Phenomenology and Cognitive Science 2: 401-414.

Kaszynski W (2000) The American Highway: The History and Culture of Roads in the United States. McFarland \& Company Inc, Jefferson, NC.

Kendall L (2002) Hanging Out in the Virtual Pub: Masculinities and Relationships Online. University of California Press, Berkeley, CA.

Lakoff G and Johnson M (1980) Metaphors We Live By. University of Chicago Press, Chicago, IL.

Lave J and Wenger I (1991) Situated Learning: Legitimate Peripheral Participation. Cambridge: Cambridge University Press. 
Leander KM and Mckim KK (2003) Tracing the everyday 'sitings' of adolescents on the Internet: A strategic adaptation of ethnography across online and offline spaces. Education, Communication, \& Information 3: 211-240.

Lemley MA (2003) Place and cyberspace. California Law Review 91: 521-542.

Lopez J (2003) Society and its Metaphors: Language, Social Theory and Social Structure. London: Continuum.

Malin BJ (2010) A very popular blog: The Internet and the possibilities of publicity. New Media \& Society 13(2): 187-202

McConnell M Middleton I Smart J and Jeffels P (2004) Exploiting historic collections on-line. Archives and Museum Informatics. Available at: http://www.archimuse.com/mw2004/papers/mcconnell/mcconnell.html (Accessed on January 10, 2012)

McCorkindale T (2010) Can you see the writing on my wall? A content analysis of the Fortune 50's Facebook social networking sites. Public Relations Journal 4(3): 114.

Miller D (1988) Appropriating the state on the council estate. Man New series 23(2): 353-372.

Mitchell WJ (1996) City of Bits: Space, Place, and the Infobahn. The MIT Press, MA, Cambridge.

Pachucki MA and Breiger, RL (2010) Cultural holes: Beyond relationality in social networks and culture. The Annual Review of Sociology 36: 205-224.

Papacharissi Z (2002) The virtual sphere. New Media \& Society 4(1): 9-27.

Piller F Schubert P Koch M and Moslein K (2005) Overcoming mass confusion: Collaborative customer co-design in online communities. Journal of Computer-Mediated Communication 10(4): 1-25.

Pinch TJ and Bijker WE (1987) The social construction of facts and artifacts. In: Bijker WE Hughes TP and Pinch TJ (eds) The Social Construction of Technological Systems: New Directions in the Sociology and History of Technology. Cambridge Mass: MIT Press.

Rheingold H (1993) The Virtual Community: Homesteading in the Electronic Frontier. Boston, MIT Press. 
Ricoeur P (1977) The Rule of Metaphor: The Creation of Meaning in Language. Toronto: University of Toronto Press.

Rosenzweig R (1979) Middle-class parks and working-class play: The struggle over recreational space in Worchester Massachusetts 1870-1910. Radical History Review 21: 31-46.

Sardar Z Ravetz JR (1996) Cyberfutures. New York: NYU Press.

Sawhney H (1992) The public telephone network: Stages in infrastructure Development.

Telecommunications Policy 538-552.

Sawhney H (2007) Strategies for increasing the conceptual yield of new technologies research. Communication Monographs 74(3): 395 - 401

Sassen S (2002) Towards a sociology of information technology. Current Sociology 50(3): 365-388.

Scheidt LA and Wright E (2010) Common visual design elements of weblogs. Retrieved on January 10, 2012 from website: http://indiana.academia.edu/documents/0009/4580/Common_Visual_Design_Elements.p $\underline{\mathrm{df}}$

Schmeidt CM (2002) Metaphor and cognition: A cross-cultural study of indigenous and universal constructs in stock exchange reports. Electronic Journal of Intercultural Communication 5: 1-17.

Shi M (1998) From imperial gardens to public parks: The transformation of urban space in early twentieth-century Beijing. Modern China 24(3): 219-254.

Shragge J and Bagnato S (1984) From footpaths to freeways. Ontario Ministry of Transportation and Communications, Historical Committee: Pennsylvania State University.

Shum S (1990) Real and virtual Spaces: Mapping from spatial cognition to hypertext. Hypermedia 2(2): 133-158.

Smith MK (2003) Issues in Cultural Tourism Studies. Routledge: UK.

Srinivasan R and Huang J (2005) Fluid ontologies for digital museums. International Journal on Digital Libraries 5(3): 193-204.

Stefik M (1996) Internet Dreams, Archetypes, Myths, and Metaphors. Cambridge: MIT Press. 
Thaler RH, Sunstein CR, and Balz JP (2010). Choice architecture. Available at:

http://ssrn.com/abstract=1583509 (Accessed on 10 January 2012)

Yen CA (2002) Western frontier or feudal society? Metaphors and perceptions of cyberspace. Berkeley Technology Law Journal 1207-1263. Available at: http://www.law.berkeley.edu/journals/btlj/articles/vol17/Yen.stripped.pdf (Accessed on 10 January 2012)

Wilson MI (2001) Location location location: The geography of the dot com problem. Environment and Planning B: Planning and Design 28: 59- 71.

CHART I:

\begin{tabular}{|c|c|c|c|}
\hline \multicolumn{2}{|c|}{ CHART I: } & Cyberspace & Typologies of \\
\hline & $\begin{array}{l}\text { TYPES OF } \\
\text { SPACE }\end{array}$ & PLACE AS METAPHOR & $\begin{array}{l}\text { VIRTUAL SPACE ISSUES/ } \\
\text { FOCUS }\end{array}$ \\
\hline 1 & Utilitarian-driven & highways & $\begin{array}{l}\text { information infrastructures, digital } \\
\text { divide, online traffic, virtual } \\
\text { communities, shared space, } \\
\text { convergence }\end{array}$ \\
\hline 2 & Aesthetic-driven & homes & $\begin{array}{l}\text { customization, personalization, } \\
\text { ownership, taste, private versus public } \\
\text { space }\end{array}$ \\
\hline 3 & Context-driven & parks & $\begin{array}{l}\text { cyberleisure, social network sites, } \\
\text { situated activity online; gendering } \\
\text { online space; online pluralism }\end{array}$ \\
\hline 4 & Play-driven & playgrounds & $\begin{array}{l}\text { engagement, interactivity, corporate } \\
\text { blogging, work-play, hard play, } \\
\text { gaming }\end{array}$ \\
\hline 5 & Value-driven & museums & $\begin{array}{l}\text { emotion, affective spaces, nationalism } \\
\text { and online tourism, digital flaneur and } \\
\text { browsing, politics of information }\end{array}$ \\
\hline
\end{tabular}

Typologies of

\footnotetext{
i Hollings Report on the Communications Competitiveness and Infrastructure
Modernization Act of 1990. Senate Committee on Commerce, Science; and Transportation,
GPO Sept 12, 1990:

i Hollings Report on the Communications Competitiveness and Infrastructure
Modernization Act of 1990. Senate Committee on Commerce, Science; and Transportation,
GPO Sept 12, 1990:

${ }^{\mathrm{i}}$ Hollings Report on the Communications Competitiveness and Infrastructure
Modernization Act of 1990. Senate Committee on Commerce, Science ; and Transportation,
GPO Sept 12, 1990: ii www.patchadams.org
} 